\title{
Sociocultural and geographical disparities in immunization among different geographical regions of Maharashtra
}

\author{
Rushikesh Khadse ( $\nabla$ rushikeshkhadse@gmail.com ) \\ International Institute for Population Sciences \\ Badal Thool \\ International Institute for Population Sciences \\ Sunil Sarode \\ International Institute for Population Sciences
}

\section{Research Article}

Keywords: Immunization, Geographical regions, Maharashtra

Posted Date: September 28th, 2021

DOI: https://doi.org/10.21203/rs.3.rs-929468/v1

License: (c) (1) This work is licensed under a Creative Commons Attribution 4.0 International License. Read Full License 


\section{Abstract \\ Background}

In Maharashtra, child immunization is an essential factor in maternal and child health services and effective in reduced child morbidity and mortality. The study focuses on the prevalence of child immunization in different geographical regions of Maharashtra. It also depicts the immunization status (no immunization, partial immunization, and full immunization) according to various socio-demographic characteristics and determinants of full Immunization and partial Immunization among children of age 12-23 months in Maharashtra

\section{Data source and Methodology:}

The fourth round of the National Family Health Survey (NFHS-4) has been used for this study. The univariate analysis and simple chi-square test were conducted to test association. The Multinomial logistic regression model was conducted to determine the determinants of partial and full immunization.

\section{Result}

In the wealth category, the middle and richest are more likely to receive full immunization than the poorest people statically significant effect. In religion, Muslims less likely to receive full Immunization, and Buddhists more likely to use full immunization compare to Hindu people. In the different geographical regions of Maharashtra, North-Maharashtra, West-Maharashtra, Konkan is less likely to have full immunization correspond to the Vidarbha region. Mothers who have any media exposure are more likely to have full immunization compare to no media exposure.

\section{Conclusions}

To conclude, the study shows a need to adopt a multi-pronged strategy while formulating an action plan for immunization by keeping in mind that vaccination is a right of every child. An appropriate proportion of childhood immunization is required to develop "Herd Immunity" to protects other unimmunized children. The most "efficient" and "equitable" way should be chosen to deliver vaccination services to identify the population's risk group. Who has remained unimmunized? As immunization in the different geographical regions in Maharashtra remained very far from the target set by Mission Indradhushya. Hence, there is a need to focus more on responsible socio-demographic factors while implementing immunization services.

\section{Background}

The distributive approach in health and health inequality is becoming influential global health agenda (Lauridsen et al. 2011). Millennium development goal (MDG) has emphasized formulating the targets to measure the country-level achievements; childhood immunization is a crucial part of maternal and child health services and one of the essential health indicators among them. 'Sustainable immunization' coverage was one of the major concerns during the 65th world health assembly held in 2012. Collective efforts by the global public health community led to a call for "Decade of Vaccine," which proposed the full benefits of immunization to all people, regardless of where they are born, who they are, or where they live. WHO, UNICEF in 2002, introduced the concept of 'reaching every district' now times has come to recast it as a 'Reaching Every Community and need of recognition immunization as a core component of the human right to health (Vashistha, 2012). The report of Global Vaccine Action Plan, 2014 noted that a third of the world's 194 countries were failing to reach $90 \%$ coverage in 2013 (2014, Assessment Report of the Global Vaccine Action Plan). The WHO's report noted that 65 countries had failed to achieve either $90 \%$ immunization nationally or 805 coverage in every district or similar administrative unit against diphtheria, tetanus, and whooping cough by 2015 (Figueiredo et al.; 2016).

There were provisions for maternal and child health $(\mathrm{MCH})$ in India during the ' 60 s. Still, due to emphasis on the family, this program lacked a systematic and practical approach. Since 1974 it has been started to set up a target for the services such as Antenatal Care (ANC), delivery, and Immunization for the mother and her child, the government also launches various schemes regarding immunization, and in this way, the MCH program has gained importance (De et al.; 2002). In India, childhood immunization is one of the most cost-effective programs. In fact, Under UIP (Universal Immunization Program now known as Mission Indradhanush), immunization provides free of cost against 12 vaccinepreventable diseases intending to avert mortality and morbidity due to these diseases. And to fully vaccinated at least $85 \%$ of all infants at the age of 1 year poses an intimating challenge to the public health agenda as profound progress is yet to be seen (Jatti et al., 2017).

Page $2 / 12$ 
National Population policy has been insisted on universal immunization coverage in India. It is the first country that adapts to the WHO's Expanded Immunization Programme, and remarkable progress has been registered in reducing disease burden since its inception, but it remained unacceptably high compared to other developing countries (Purohit et al.; 2017). The stalled and uneven progress of childhood vaccination in India could result from a complex set of factors associated with the demand for and supply of the vaccines (Prusty et al.,2014). Drop out to different doses of full immunization remains the major challenge in child health; in India, only $62 \%$ of the children aged 12-23 months are fully vaccinated by the fourth round of the National Family Health Survey (NFHS-4). The previous study observed the trend and pattern of inequality in child immunization across the region. It led to the argument that the theory of the "inverse equity hypothesis" persisted in India. The theory itself argues that "absolute health inequalities would increase in the short term and would only decline as the intervention gradually reaches the most deprived sectors of the population." Rural and girl children received benefits in those regions, which observed an increase in average full immunization coverage during 1992-2006 (Singh (2013); Khan et al., 2018).

In the Indian states, there is lagging of appropriateness among vaccination timing. The county is a significant shareholder in unimmunized children globally; therefore, it is crucial to understand the immunization pattern across different geographies in India (Panda, 2020). One of the most noticeable findings in the National Family Health Survey over the years has been a decline in the number of fully immunized children's that is the figures have come down from $78.4 \%$ in NFHS-2 to 58.8\% in NFHS-3 and the present 56.3\% in NFHS-4 (Natu et al., 2020). As per the fourth round of the District Level Household Survey (DLHS-4), only $65.3 \%$ of children in Maharashtra were fully immunized (Gawade et al., 2021). For the dismal UPI achievement in India, managerial, administrative, and government-related inadequacies are responsible rather than technical or financial inadequacies, and the state is responsible for the implementation of immunization, so it is essential to investigate the regional variation of immunization coverage across the state (Vashistha, 2012).

Kumar (2011) recorded that spatial pattern in immunization coverage in India is quite puzzling, demographically backward states like Uttar Pradesh, Bihar, and Orissa exhibiting an increase in immunization coverage while decline can be seen economically progressive states like Gujarat and Maharashtra. In the Coverage Evaluation Survey conducted by the Ministry of Health and Family Welfare, over $80 \%$ of the complete vaccination records up to 12 months and a meager non-vaccination rate of only $2 \%$. Maharashtra is the participating state in the global post-marketing surveillance network to report AEFI (Adverse Events Following Immunization) associated with the new vaccine (Vashistha, 2012).

To Assess the Level of Child immunization in Different Geographical Regions of Maharashtra. Maharashtra is divided into five geographical regions: Vidarbha, Marathwada, North-Maharashtra, West-Maharashtra, and Konkan. Vidarbha region contains 11 districts, Marathwada has eight districts, North-Maharashtra consists of five districts, and the West- Maharashtra has only five districts. Konkan part of Maharashtra is essential because it contains the capital of the state (Mumbai), consist of seven districts. Maharashtra has 36 districts, but at the time of the NFHS-4 survey, it has only 35 districts.

The economy in Maharashtra has become metropolises highly. Though there is a high economic development, Maharashtra suffers from acute regional inequality. About half of the total income for the state accounted only by the Konkan region; western Maharashtra is the next highest developed region and if followed by Vidarbha and Marathwada (Shaban, 2006). Weak immunization performance in such an undeveloped geographical region may also indicate system failure in reaching the underprivileged population; also, immunization services themselves may be inadequate or ineffective in such areas (Pande et al., 2002). There is a need to check whether the slow-down in immunization coverage is because of supply-side constraints or a change in the program's priority. It is a worrying factor that the decline in immunization among the poor in a progressive state like Maharashtra (Mohanty \& Pathak, 2009). As there is a lack of data on various determinants of partial immunization coverage in Maharashtra, which is deemed a better progressive state (Natu et al., 2020), this study will investigate the immunization level and determine various associated factors Maharashtra. Hence, the present study plan to determine the immunization status and the determinants of partial and full immunization among children aged 12-23 months in Maharashtra.

\section{Data Source And Methodology}

The fourth round of the National Family Health Survey 2015-16 has been used in this study to investigate the effect of selected background characteristics on immunization coverage. The dataset provides information about the vaccination status of children born in five years preceding the survey. The line of other Demographic Health Surveys (DHS) comprises a wide range of topics like Fertility, Mortality, family planning, immunization coverage, and nutritional status among children. The data recorded based on a vaccination card (interviewer note down each vaccination against the disease and date of it) or mothers' recall about vaccination except the date of vaccination (if vaccination card is not available).

The measure of a child's immunization is a binary outcome, and it was calculated on whether a child aged 12-23 months (age group considers according to WHO schedule of immunization) has been administered all the six vaccinations or not. But in this paper, we have

Page $3 / 12$ 
calculated three outcome variables of immunization as following 1) No immunization, 2) Partial immunization 3) Full immunization.

Full immunization: children in the age group of 12-23 months who have received one vaccination of BCG, Measles, and three doses each of DPT and Polio (exclude polio 0) are considered fully immunizations NFHS-4.

No Immunization: children in the age group of 12-23 months who have not received any vaccination are considered non-immunized as per NFHS-4.

Partial Immunization: Children in the age group of 12-23 who received at least one vaccination but not all the vaccination are considered partially immunized as per NFHS-4.

We have shown differentials of immunization according to the following socio-economic characteristics- age of the mothers, childbirth order, place of residence, education of mother, religion, caste/tribe, wealth index, region of Maharashtra.

As the meaningful prevalence of vaccination is available, we have used Relative Risk's computation over the Odds Ratio in this study (Schmidt et al., 2008). also checking association between the following characteristics on immunization outcomes-mothers exposure to mass media, Children Ever Born, Body Mass Index, ANC visits, Sex of child, Children's age, and Morbidity status of children.

\section{Chi-square test}

The Chi-square test uses to test the independence of two attributes of a population; it compares two variables in the contingency table to see they are related or not.

The Chi-square statistic is as following

$$
\chi^{2}=\sum \frac{\left(O_{i}-E_{i}\right)^{2}}{E_{i}}
$$

Where,

$\chi 2_{c}=$ Chi square with ' $c$ ' Degree of freedom,

$O_{i}=$ Observed value

$E_{i}=$ Expected valueChi square statistic with p-value less than 0.05 means variables under consideration are significantly related.

\section{Relative Risk Ratio}

A Relative Risk Ratio is a ratio of two probabilities. (The relative risk is also called the risk ratio).

\begin{tabular}{|l|l|l|}
\cline { 2 - 3 } \multicolumn{1}{c|}{} & Event & No Event \\
\hline Treatment & a & b \\
\hline Control & c & d \\
\hline
\end{tabular}

From this table, the probability of an event in the treatment group is $a /(a+b)=R 1$; similarly probability of an event in the control group is $c /(c+d)=R 2$. So the Relative Risk Ratio (RRR) or Risk Ratio will be the ratio of these two probabilities that is R1/R2

$$
R R R=\frac{\text { Risk of the event in treatment group }}{\text { Risk of the event in control group }}=\frac{a /(a+b)}{c /(c+d)}
$$


In this study, the Event will be Immunization status for partial and full immunization. We have computed the Relative Risk Ratio of immunization coverage for various socio-economic characteristics.

If $\mathrm{RRR}=1$, Association of socioeconomic characteristics with immunization is in question or No association;

If RRR is greater than 1, this is evidence of positive association and may be causal;

If RRR is less than 1 , this is evidence of negative association, indicating a protective effect.

Statistical analyses have done using Stata (version13) software.

\section{Result}

Figure 1 shows the status of child immunization in different geographical regions of Maharashtra. The full immunization is highest in the Vidarbha region with 57.4 percent and lowest in North Maharashtra with 41.9 percent, followed by Maharashtra, West-Maharashtra, Marathwada, and Konkan, respectively. Marathwada has the highest utilization of partial immunization with 44.7 percent and lowest with 37.1 percent Vidarbha in a geographical region. Konkan has the highest no immunization with 14.3 percent and lowest in Vidarbha, 5.5 percent, followed by North-Maharashtra, West-Maharashtra, and Marathwada.

Table 1 Percentage of Immunization by Background Characteristic Last Live Birth 12-23 Month in The Five Year Preceding the survey in Maharashtra 2015-16. 


\begin{tabular}{|c|c|c|c|c|c|}
\hline \multicolumn{6}{|c|}{ Type of Immunization } \\
\hline Background characteristic & No Immunization & Partial Immunization & Full Immunization & $\mathrm{P}$ *-Value & $\mathbf{n}$ \\
\hline \multicolumn{6}{|l|}{ Age Group } \\
\hline $25-34$ & 11.05 & 38.79 & 50.16 & $\mathrm{P}=0.000$ & 5,005 \\
\hline$>34$ & 13.98 & 36.45 & 49.57 & 438 & \\
\hline \multicolumn{6}{|l|}{ Child Birth Order } \\
\hline 1 & 9.59 & 43.82 & 46.58 & 2,456 & \\
\hline 2 & 9.75 & 39.95 & 50.3 & $\mathrm{P}=0.000$ & 4,094 \\
\hline 3 & 12.9 & 40.66 & 46.44 & 1,754 & \\
\hline $4+$ & 15.86 & 47.61 & 36.53 & 316 & \\
\hline \multicolumn{6}{|l|}{ Place of Residence } \\
\hline Urban & 10.6 & 40.48 & 48.92 & $\mathrm{P}=0.96$ & 3,026 \\
\hline Rural & 11.02 & 42.93 & 46.06 & 6,084 & \\
\hline \multicolumn{6}{|l|}{ Education of Mother } \\
\hline No Education & 16.34 & 49.34 & 34.32 & 965 & \multirow{4}{*}{592} \\
\hline Primary & 12.42 & 42.08 & 45.5 & $\mathrm{P}=0.000$ & \\
\hline Secondary & 10.27 & 41.91 & 47.81 & 4,960 & \\
\hline Higher & 9.56 & 39.02 & 51.42 & 2,593 & \\
\hline \multicolumn{6}{|l|}{ Religion } \\
\hline Hindu & 10.4 & 41.49 & 48.11 & 6,827 & \\
\hline Muslim & 15.16 & 41.49 & 43.35 & $\mathrm{P}=0.000$ & \multirow[t]{3}{*}{1,392} \\
\hline Buddhist & 8.12 & 44 & 47.88 & 799 & \\
\hline Others & 1.84 & 51.08 & 47.08 & 92 & \\
\hline \multicolumn{6}{|l|}{ Caste/Tribe } \\
\hline SC & 10.99 & 42.33 & 46.68 & 1,525 & \\
\hline ST & 11.82 & 46.11 & 42.07 & $\mathrm{P}=0.000$ & \multirow[t]{3}{*}{1,423} \\
\hline $\mathrm{OBC}$ & 8.49 & 37.91 & 53.6 & 2,446 & \\
\hline Others & 11.67 & 42.33 & 45.99 & 3,716 & \\
\hline \multicolumn{6}{|l|}{ Wealth } \\
\hline Poorest & 13.96 & 44.83 & 41.21 & 2,396 & \\
\hline Poorer & 9.81 & 43.46 & 46.74 & $P=0.000$ & \multirow{4}{*}{2,181} \\
\hline Middle & 9.64 & 42.44 & 47.93 & 1,818 & \\
\hline Richer & 12.62 & 37.71 & 49.67 & 1,552 & \\
\hline Richest & 6.92 & 39.75 & 53.33 & 1,163 & \\
\hline \multicolumn{6}{|l|}{ Region } \\
\hline Vidarbha & 5.53 & 37.05 & 57.42 & 2,737 & \multirow{3}{*}{2,642} \\
\hline Marathwada & 7.78 & 44.65 & 47.57 & $P=0.000$ & \\
\hline North Maharashtra & 13.9 & 44.22 & 41.89 & 1,465 & \\
\hline West Maharashtra & 11.35 & 40.43 & 48.22 & 1,177 & \\
\hline Konkan & 14.25 & 42.56 & 43.19 & & 1,089 \\
\hline Total & 10.83 & 41.85 & 47.32 & & 9,110 \\
\hline
\end{tabular}

Table 1 shows the immunization coverage according to different background characteristics and association between type of immunization and different background characteristics. Mothers in the age group of 25-34 have a high percentage of full immunization, $50.16 \%$, and mothers less than 24 years have the lowest prevalence of full immunization. Mother's full immunization increases for the second child but drops it for third and above birth order. The percentage of No immunization rises with an increase in birth order. Full immunization shows an association with 48.92 percent in urban areas with 46.06 percent in rural areas. No immunization and partial immunization percentage were found to decrease while full immunization percent increased with an increase in the level of mother's education. Only 34.32 percent of women who received full immunization with no education and 51.42 percent of women with higher education receive full immunization. Among Hindu, 48.11 percent receive full immunization, followed by Buddhists with 47.88 percent and Muslims with 43.35 percent. A high percentage of no immunization and the lowest level of full immunization observe among Muslim women with $15.16 \%$ and $43.35 \%$. The 
highest rate is $51.08 \%$ of partial immunization recorded among women marked as other relation. Mothers from the OBC category with the lowest percentage of no immunization and partial immunization also possess the highest rate of full immunization compared to the rest of the category.

Fifty-three percent of a mother who belongs to the OBC category receives full immunization while only 42.07 percent ST women receive full immunization. As the wealth quintile increases, the level of full immunization also increases. Still, in the case of no immunization, the poorest and richer mothers are almost the same. The percentage of no immunization is high among the richest compared to the rest of the wealth quintile. Only 41.21 percent of the poorest women receive full immunization compared to the richest women receiving 53.33 percent full vaccination. The association is found between the region and the type of immunization. In different geographical regions of Maharashtra, 57.42 percent of women received full Immunization in the Vidarbha region, followed by West-Maharashtra, Marathwada, Konkan, and North-Maharashtra, with the lowest 41.89 percent of women receive the full vaccination. Vidarbha region has the lowest percentage of no immunization and partial immunization coverage and the highest percentage of full immunization coverage.

Table 2 Relative Risk Ratio for Partial and Full Immunization by different background characteristics in Maharashtra 2015-16 


\begin{tabular}{|c|c|c|}
\hline \multirow[t]{2}{*}{ Background characteristics } & \multicolumn{2}{|c|}{ Type of Immunization } \\
\hline & PARTIAL IMMUNIZATION & FULL IMMUNIZATION \\
\hline & RRR1 & RRR2 \\
\hline \multicolumn{3}{|l|}{ Wealth } \\
\hline \multicolumn{3}{|l|}{ Poorest ${ }^{\circledR}$} \\
\hline Poorer & $1.103(0.8411 .446)$ & $1.187(0.9031 .56)$ \\
\hline Middle & $1.275(0.9191 .768)$ & $1.588 * * *(1.1442 .205)$ \\
\hline Richer & $1.108(0.7721 .59)$ & $1.393 *(0.972 .001)$ \\
\hline Richest & $1.691^{* *}(1.0962 .608)$ & $1.676 * *(1.0852 .588)$ \\
\hline \multicolumn{3}{|l|}{ Religion } \\
\hline \multicolumn{3}{|l|}{ Hindu ${ }^{\circledR}$} \\
\hline Muslim & $0.79 *(0.6031 .034)$ & 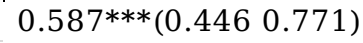 \\
\hline Buddhist & $1.434(0.9232 .228)$ & $1.475 *(0.952 .29)$ \\
\hline Others & $3.982 *(0.94616 .763)$ & $2.788(0.65811 .814)$ \\
\hline \multicolumn{3}{|l|}{ Caste/tribe } \\
\hline \multicolumn{3}{|l|}{$\mathrm{SC} \circledast$} \\
\hline ST & $1.39 *(0.9572 .02)$ & $1.409 *(0.9662 .054)$ \\
\hline $\mathrm{OBC}$ & 1.215 (0.863 1.709) & $1.328(0.9441 .868)$ \\
\hline Others & $1.108(0.8021 .531)$ & $1.133(0.821 .567)$ \\
\hline \multicolumn{3}{|l|}{ Regions } \\
\hline \multicolumn{3}{|l|}{ Vidarbha ${ }^{\circledR}$} \\
\hline Marathwada & $1.113(0.8491 .459)$ & $0.862(0.6591 .129)$ \\
\hline North Maharashtra & $0.63^{* * *}(0.4760 .833)$ & $0.378 * * *(0.2860 .501)$ \\
\hline West Maharashtra & $0.63^{* * *}(0.4630 .857)$ & $0.417^{* * *}(0.3070 .567)$ \\
\hline Konkan & $0.659 * * *(0.4840 .897)$ & $0.478^{* * *}(0.3520 .649)$ \\
\hline \multicolumn{3}{|l|}{ Media Exposure } \\
\hline \multicolumn{3}{|l|}{ No media exposure ${ }^{\circledR}$} \\
\hline Any Media exposure & $1.35^{* *}(1.0731 .699)$ & $1.501^{* * *}(1.1891 .895)$ \\
\hline \multicolumn{3}{|l|}{$\begin{array}{l}\text { Mother's age } \\
<24 \AA\end{array}$} \\
\hline 25-34 years & $0.79^{* *}(0.6410 .973)$ & $1.298 * *(1.051$ 1.602) \\
\hline$>34$ years & $0.709(0.4611 .093)$ & $1.612^{* *}(1.0492 .478)$ \\
\hline \multicolumn{3}{|l|}{$\begin{array}{l}\text { mother's education } \\
\text { no education }{ }^{\circledR}\end{array}$} \\
\hline Primary & $1.039(0.6921 .559)$ & $1.62 * *(1.072 .453)$ \\
\hline secondary & $1.153(0.8571 .552)$ & $1.668 * * *(1.2252 .27)$ \\
\hline Higher & $1.042(0.7251 .497)$ & $1.461 * *(1.0092 .117)$ \\
\hline \multirow{2}{*}{\multicolumn{3}{|c|}{$\begin{array}{l}\text { CEB } \\
1 \AA\end{array}$}} \\
\hline & & \\
\hline 2 & $0.899\left(\begin{array}{l}0.718 \\
1.125\end{array}\right)$ & $0.88(0.7031 .101)$ \\
\hline 3 & $0.888(0.6651 .185)$ & $0.711^{* *}(0.5320 .951)$ \\
\hline $4+$ & $0.876(0.606$ 1.267) & $0.55^{* * *}\left(\begin{array}{lll}0.377 & 0.802\end{array}\right)$ \\
\hline \multicolumn{3}{|l|}{ BMI } \\
\hline \multicolumn{3}{|l|}{ Underweight ${ }^{\circledR}$} \\
\hline Normal & 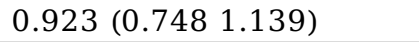 & $0.94\left(\begin{array}{lll}0.761 & 1.162\end{array}\right)$ \\
\hline Overweight & $0.63^{* * *}(0.4690 .845)$ & $0.759 *(0.567$ 1.017) \\
\hline \multicolumn{3}{|l|}{ ANC } \\
\hline \multicolumn{3}{|l|}{ No ANC ${ }^{\circledR}$} \\
\hline Full ANC & $1.199 *(0.9761 .474)$ & $1.327^{* * *}(1.081$ 1.629) \\
\hline \multicolumn{3}{|l|}{$\begin{array}{l}\text { Sex of Child } \\
\text { male }{ }^{\circledR}\end{array}$} \\
\hline Female & 1.069 (0.894 1.277) & $0.993(0.831 .188)$ \\
\hline \multicolumn{3}{|l|}{ Child's Age } \\
\hline $13-23$ months & $0.941(0.751 .182)$ & $2.035^{* * *}(1.6292 .543)$ \\
\hline Morbidity & & \\
\hline No morbidity ${ }^{\circledR}$ & & \\
\hline Any morbidity & $1.028(0.7851 .345)$ & $0.97(0.741 .273)$ \\
\hline
\end{tabular}

Table 2 illustrates the result of multinomial logistic regression to determine the association of various background characteristics with partial Immunization and full Immunization. The North-Maharashtra (RRR=0.63 Cl 0.476-0.833), West-Maharashtra (RRR=0.63, Cl 0.463- 
0.857), and Konkan (RRR=0.659, $\mathrm{Cl}$ 0.484-0.897) are less likely to partial immunization while comparing to the Vidarbha region. A similar pattern has been observed in full immunization that is North-Maharashtra 62\% significantly less likely $(\mathrm{RRR}=0.378, \mathrm{Cl} 0.286-0.501)$, WestMaharashtra 59\% significantly less likely (RRR=0.417, Cl 0.307-0.567) and Konkan 52\% significantly less likely (RRR=0.478, Cl 0.352-0.649) of having full immunization as compare to Vidarbha region. In addition to this, mothers from Marathwada are less likely to have full immunization than in the Vidarbha region.

Wealth quintile found significantly associated with full immunization level. Middle, Richer and Richest wealth quintile mothers are more likely to have full immunization than the poorest mother. In terms of religion, Muslim mothers are significantly less likely to have partial Immunization (RRR=0.79, Cl 0.603-1.034) and full immunization (RRR=0.587, $\mathrm{Cl} 0.446-0.771$ ) to Hindu mothers. Scheduled Tribe, women are significantly 1.39 times more likely to have partial immunization than the Scheduled Caste $(\mathrm{RRR}=1.39, \mathrm{Cl} 0.957-2.02)$. Mothers of age group 25 to 34 years have $21 \%$ less likely to partial immunization compare to below 24 age group $(\mathrm{RRR}=0.79, \mathrm{Cl} 0.641-0.973)$. But as inverse mothers from the age group 25-34 years 1.3 times (RRR=1.298, $\mathrm{Cl} 1.051-1.602)$ and above 34 years are 1.6 times $(\mathrm{RRR}=1.612$, $\mathrm{Cl} 1.049-2.478$ ) significantly more likely to have full immunization as compared to mothers of aged less than 25 years. The mothers who avail full ANC have found they bring their children significantly more likely for partial (RRR=1.199, Cl 0.976-1.474) and full immunization (RRR=1.327, Cl 1.081-1.629) when compared to mothers who don't receive ANC.

When it comes to mass media exposure, the mothers exposed to any media are significantly more likely to go for partial (RRR=1.35, $\mathrm{Cl} 1.073$ 1.699) and full immunization (RRR=1.501, $\mathrm{Cl} 1.189-1.895$ ) as compared to mothers with no media exposure. In terms of education, mothers who completed primary and secondary education are significantly more likely to go for a child's full immunization that is 1.62 times and 1.66 times, respectively, than illiterate mothers. Mothers having three children birth (RRR=0.711, $\mathrm{Cl} 0.532-0.951)$ and above four childbirth (RRR=0.55, Cl 0.377-0.802) are significantly less likely to have full immunization than mothers having one child. In terms of Body Mass Index, Overweight mothers are $37 \%$ significantly less likely to go for children's partial Immunization (RRR=0.63, Cl $0.469-0.845)$ and $24 \%$ significantly less likely to go for full Immunization (RRR=0.759 Cl 0.567-1.017) as compared to Underweight mother. Sex of child didn't find significantly associated with partial and full immunization in our analysis. A similar result has been found in terms of morbidity of a child whose morbidity status of children doesn't found significantly associated with partial and full immunization coverage.

\section{Discussion}

In the present study, it was found that the Vidarbha region in Maharashtra has the highest full immunization level and lowest partial and no immunization compared to the rest of the region in Maharashtra. The observation that any of the geographical regions don't fulfill the national target (90\%) of full immunization coverage set by Mission Indradhanushya and this much level is needed to disrupt disease transmission also this will protect unimmunized children due to "Herd Immunity" (Malkar et al.,2013). all geographical regions in Maharashtra are not even close to this target.

While comparing with the Vidarbha region, Northern Maharashtra, west Maharashtra, and Konkan are significantly less likely to have partial immunization. Other determinants like Mass media exposure, mother age, and BMI status of mothers are also significantly associated with Partial immunization coverage in Maharashtra. Many studies on full immunization levels conducted in various districts of different geographical regions in Maharashtra show inconsistent findings with our research showing a significantly higher vaccination rate, studies like Malkar et al.,2013 (78.57\%); Khargekar et al.,2015 (71.1\%).

Mass media exposure and mother's education were found significantly associated with full immunization in our study (Gupta et al., 2013) proclaims the reason for un immunization was rumor and ignorance, which could be changed with proper health education. Similar line results observed in the study (Gatchell et al.,2008), exposure to television was the most vital determinant of childhood immunization in Bihar.

Our study shows a slightly higher rate of full immunization in urban areas than in rural areas (Khan et al.,2020), probably because of the better accessibility and success of the "supply-side" factors. Significant inequality based on economic status has been observed even in a better progressive state like Maharashtra (Mathew et al.,2012) similar type of association of wealth index with immunization has been highlighted in our study.

Sex of the children and morbidity status of children doesn't found associated with types of immunization in our analysis akin results have been depicted in the study (Kar et al.,2001), morbidity status of children found the third leading reason for partial immunization in the survey of Wagh et al.,2013. as our study reveals, Muslim mothers are less likely to go for child immunization similar type of significant influence of religion on immunization status also documented in the study (Malkar et al.,2013). Various socioeconomic, cultural, behavioral, and other factors related to religion could be responsible for this. Children with birth orders greater than two are less likely to go for full immunization than first-order birth. And this found consonant with literature; one possible reason for this could be, till the second and above children

Page $9 / 12$ 
mothers started to believe that immunization is risky or unnecessary due to the misleading facts like firstborn child experienced some adverse reaction to immunization or other children in the community, despite being immunized they did not contract the disease.

A slight association between caste status with immunization has been found in our study similar type of findings illustrated in the study of (Gatchell et al. 2008) Validate the association of caste status with complete childhood immunization in Maharashtra. While the research Sharma (2007) documented that there are no substantial differences in immunization coverage among the children of scheduled caste, scheduled tribes, and other backward classes. However, the range is marginally low among scheduled tribes. However, coverage among the children of different caste groups is much higher.

The present study illustrates that the mothers who had availed full ANC are more likely to have full children Immunization; however, similar findings also observed in partial immunization. In line with this, the study (De et al.,2002) put forward the same type of observation. One possible reason behind this is interaction at ANC enhancing mothers' knowledge about the benefits of avail MCH services. Various studies proposed that partial immunization were visited the native place or other sibling are not well and inconvenient time of Immunization (Khargekar et al.,2015). Still, due limitation of data, we couldn't consider that during analysis. To put forward advice for maximizing the full immunization stated as to sustain the contact with a parent for the time between different doses of vaccination and hold the parent's attention during the non-immunization period. It will be adequate to provide some health care packages under maternal and child health (Sharma et al., 2009).

\section{Conclusion}

The coordinated effort and effective action plan are base on the multi-pronged strategy required to achieve universal immunization coverage in India (Jatti et al., 2017). Wealth status finds significantly associated with immunization status in our study; vaccination is a fundamental right of every child. In 1946, the government's appointed 'Bhore Committee also stated that health care is a fundamental right, not a commodity. The immunization program will run so that the system should pay incentives as it involves other costs like travel costs to reach the site, opportunity cost, and a day spent there instead of work (Pande et al.,2003).

Khan et al., 2020 reported that among schedule tribe children, immunization coverage had been found lowest. The possible reason could be poverty and illiteracy, as most of them belong to the low wealth quintile. The first constraint of these studies is that we couldn't establish causal inference from the observed relationship due to the cross-sectional design of these studies. The second limitation is there may be a chance of recall bias as responses regarding immunization were based on vaccination cards or mother recall- for mothers living in rural areas are where literacy rate among them still not satisfactory. The third limitation could be in NFHS, and there is an increased likelihood of misreporting of children's age that could exhibit selection and information bias in large-scale surveys. Strengthening the ICDS, emphasize health worker participation in implementing the immunization, organizing immunization camps regularly, and providing incentives have shown improvement in the immunization rate (Singh,2013)

There is almost non-existence of the VPD (Vaccines-Preventable Disease) surveillance system in India due to which bottleneck in monitoring. The impact of vaccination is essential to include induction of innovative methods, proper tracking of the program, improving operational efficiency, 'reaching every community, and integrated health interventions and immunization to attain full immunization.

A massive public campaign like Pulse Polio is required for the remaining vaccine to reduce partial immunization. To bring accuracy in immunization recording purposes, Health Card should be compulsory irrespective of delivery place. Vashistha 2012 also suggests an urgent need to revamp the immunization system by re-defining and re-designing roles, responsibilities, and coordination among at three-level; the center, state, and district. There is a need to strengthen program management skills at lower and mid-level managers (Sharma, 2007).

The Policymakers must formulate an action plan by considering "efficiency," which is a euphemism for performance, and "equity," which described the distribution of vaccination across the different groups because average value doesn't always reflect an accurate picture or provide information (Mathew et al.,2012). Identifying the high-risk groups to remained unvaccinated and setting up a proper action plan could also be "Equity." The developments had taken place till now in that region of vaccination are strengthening and expanding the cold chain system, also establishing a network of outreach immunization sites to alternatively vaccine delivery model, capacity building of health functionaries, drafting national vaccine policy, and tracking beneficiaries through maternal and child tracking system, etc. (Taneja et al., 2013).

\section{References}

De Figueiredo, A., Johnston, I. G., Smith, D. M., Agarwal, S., Larson, H. J., \& Jones, N. S. (2016). Forecasted trends in vaccination coverage and correlations with socioeconomic factors: a global time-series analysis over 30 years. The Lancet Global Health, 4(10), e726-e735.

Page 10/12 
De, P., \& Bhattacharya, B. N. (2002). Determinants of child immunization in Flourless-developed states of North India. Journal of Child Health Care, 6(1), 34-50.

Gatchell, M., Thind, A., \& Hagigi, F. (2008). Informing state-level health policy in India: The case of childhood immunizations in Maharashtra and Bihar. Acta Pædiatrica, 97(1), 124-126.

Gawade, S. A., Gore, H. D., \& Mane, A. B. (2021) Determinants of Immunization Status Among Children Between 13-24 Months of Age in Maharashtra, India-A Community Based Cross-Sectional Study. Vaccine Research, 28-33.

Gupta, P. K., Pore, P., \& Patil, U. (2013). Evaluation of immunization coverage in the rural area of Pune, Maharashtra, using the 30 cluster sampling technique. Journal of family medicine and primary care, 2(1), 50.

Jatti, G. M., Bandichhode, S. T., Nandimath, V. A., \& Jadhav, S. B. (2017). An evaluation of primary immunization coverage among 12-23 months old children in an urban area of Western Maharashtra: A community-based study. Indian Journal of Child Health, 4(1), 85-87.

Kar, M., Reddaiah, V. P., \& Kant, S. (2001). Primary immunization status of children in slum areas of South Delhi-the challenge of reaching urban poor. Indian Journal of Community Medicine, 26(3), 151.

Khan, J., Shil, A., \& Prakash, R. (2018). Exploring the spatial heterogeneity in different doses of vaccination coverage in India. PloS one, 13(11), e0207209.

Khan, N., \& Saggurti, N. (2020). Socioeconomic inequality trends in childhood vaccination coverage in India: Findings from multiple rounds of National Family Health Survey. Vaccine, 38(25), 4088-4103.

Khargekar, N. C., Khargekar, V. C., \& Shingade, P. P. (2015). Immunization status of children under 5 years in a tribal area, parol, thane district. National Journal of Community Medicine, 6(4), 522-527.

Kumar, A., \& Mohanty, S. K. (2011). Socio-economic differentials in childhood immunization in India, 1992-2006. Journal of Population Research, 28(4), 301.

Lauridsen, J., \& Pradhan, J. (2011). Socio-economic inequality of immunization coverage in India. Health economics review, 1(1), 1-6.

Malkar, V. R., Khadilakar, H., Lakde, R. N., Joge, U. S., \& Choudhari, S. (2013). Assessment of socio-demographic factors affecting immunization status of children in age group of 12-23 months in a rural area. Indian Medical Gazette, 164-169.

Mathew, J. L. (2012). Inequity in childhood immunization in India: a systematic review. Indian pediatrics, 49(3), $203-223$.

Mohanty, S. K., \& Pathak, P. K. (2009). Rich-poor gap in utilization of reproductive and child health services in India, 1992-2005. Journal of biosocial science, 41(3), 381.

Natu, S. A., Mhatre, S., Shanbhag, R., Captain, M., \& Kulkarni, K. (2020). Immunization status of children admitted to a tertiary hospital in India. International Journal of Contemporary Pediatrics, 7(8), 1686.

Panda, B. K. (2020). Temporal trend and inequality in immunization coverage in India. In Public Health in Developing Countries-Challenges and Opportunities. IntechOpen.

Pande, R. P., \& Yazbeck, A. S. (2002). Beyond national averages for Immunization in India: income, gender and regional inequalities. World Bank, Health, Nutrition and Population.

Pande, R. P., \& Yazbeck, A. S. (2003). What's in a country average? Wealth, gender, and regional inequalities in Immunization in India. Social science \& medicine, 57(11), 2075-2088.

Prusty, R. K., \& Kumar, A. (2014). Socioeconomic dynamics of gender disparity in childhood immunization in India, 1992-2006. PloS one, 9(8), e104598.

Purohit, L., Sahu, P., \& Godale, L. (2017). Assessment of immunization status of 12-23 month children in urban slums in Solapur, Maharashtra, India. Natl J Community Med, 8, 568-71.

SAGE, Strategic Advisory Group of Experts on Immunization, 2014 Assessment of Report of the Global VaccineActionPlan.https://www.who.int/immunization/global_vaccine_action_plan/SAGE_DoV_GVAP_Assessment_report_2014_English.pdf

Page $11 / 12$ 
(accessed May 05,2021)

Shaban, A. (2006). Regional structures, growth and convergence of income in Maharashtra. Economic and Political Weekly, $1803-1815$.

Sharma, R., Desai, V. K., \& Kavishvar, A. (2009). Assessment of immunization status in the slums of Surat by 15 clusters multi indicators cluster survey technique. Indian journal of community medicine: official publication of Indian Association of Preventive \& Social Medicine, 34(2), 152.

Sharma, S. (2007). Immunization coverage in India. Institute of Economic Growth, University of Delhi.

Singh, P. K. (2013). Trends in child immunization across geographical regions in India: focus on urban-rural and gender differentials. PloS one, 8(9), e73102.

Taneja, G., Sagar, K. S., \& Mishra, S. (2013). Routine Immunization in India: a perspective. Indian Journal of Community Health, 25(2), 188192.

Vashishtha, V. M. (2012). Status of Immunization and need for intensification of routine Immunization in India. Indian pediatrics, 49(5), 357361 .

Wagh, S., Mehendale, A., Raut, M., Wagh, S., \& Sharma, D. (2013). Evaluation Of Primary Immunization Coverage And Reasons For Partial/Non Immunization In Maharashtra. Int J Cur Res Rev, 5(15), 66-72.

\section{Figures}

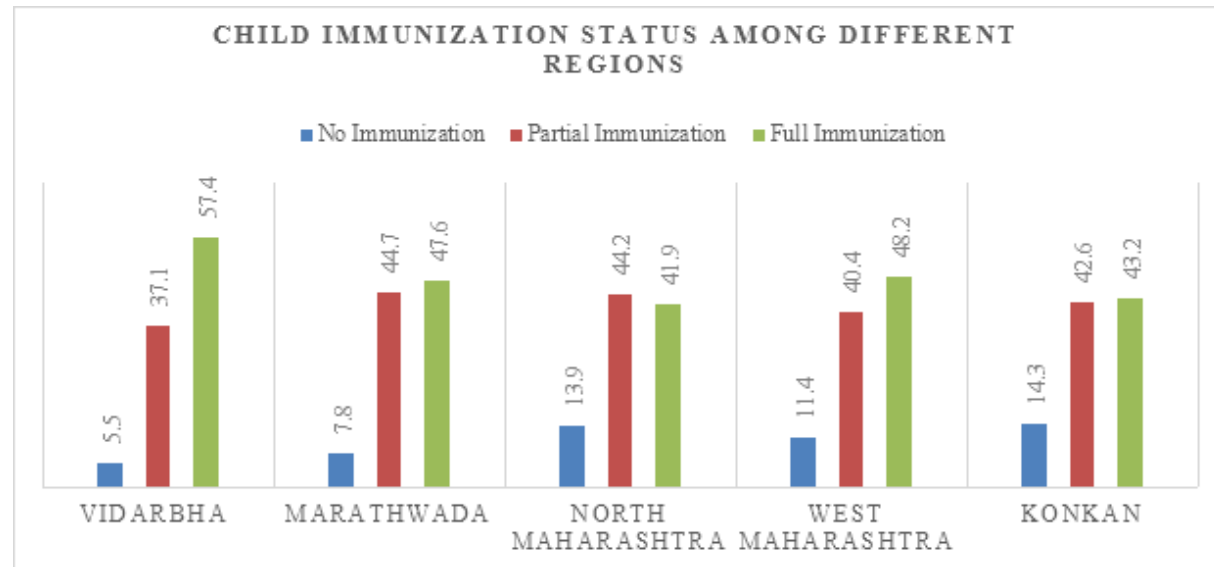

Figure 1

Status of children Immunization in Different Geographical Regions of Maharashtra, 2015-16. 